\title{
SORPTION PROPERTIES OF Cd, Cu, Pb AND Zn IN SOILS WITH SMECTITIC CLAY MINERALOGY
}

\author{
Péter SIPOS*, Réka BALÁZS, \& Tibor NÉMETH \\ Institute for Geological and Geochemical Research, Research Centre for Astronomy and Earth Sciences, Hungarian \\ Academy of Sciences, H1112 Budapest, Budaörsi út 45., Hungary *Corresponding author: sipos.peter@csfk.mta.hu
}

\begin{abstract}
Evaluation of the effect of soil properties on metals' sorption in soils is a highly complicated task due to the large heterogeneity of factors affecting this process. To lower this heterogeneity, $\mathrm{Cd}, \mathrm{Cu}, \mathrm{Pb}$ and $\mathrm{Zn}$ sorption properties of three acidic and three alkaline smectitic soils were studied in single element and competitive batch sorption experiments, and the sorption capacities of the soils were related to their major properties. Higher sorption of $\mathrm{Pb}$ and $\mathrm{Cu}$ than $\mathrm{Cd}$ and $\mathrm{Zn}$ was found also in smectitic soils, and this difference was increased by competition. In acidic soils, organic matter and smectites provides the sorption sites for $\mathrm{Pb}$ and $\mathrm{Cu}$ primarily, whereas precipitation of $\mathrm{Pb}$ as carbonate and sorption of $\mathrm{Cu}$ on soil organic matter is characteristic at alkaline conditions. Contrarily, $\mathrm{Cd}$ and $\mathrm{Zn}$ showed the highest affinity to smectites primarily if they are accumulated together with iron-oxyhydroxides. Processes affecting the shape of the sorption cure may result to misleading sorption capacity values, so an additional parameter describing the sorption of a given metal directly should be involved in the data evaluation. Cadmium and $\mathrm{Zn}$ may pose a higher risk to the environment than $\mathrm{Pb}$ and $\mathrm{Cu}$ in case of their release to the soil. However, accumulation of smectites together with iron may significantly decrease this risk. Elimination of one single variable was not enough to get a much deeper insight into soil-metal interaction, although several advantageous characteristics of smectites could be confirmed regarding metal sorption in soils.
\end{abstract}

Keywords: sorption; metal carbonate precipitation; smectite; heavy metals; soil

\section{INTRODUCTION}

Heavy metals are natural components of soils. Their main source is rock mineral weathering and their concentrations remain mostly below toxic levels in uncontaminated soils. The study of their sorption characteristics in soils is of primary importance both from agricultural and environmental point of view, as some of them are essential trace elements (such as $\mathrm{Cu}$ and $\mathrm{Zn}$ ) while others are among the most hazardous metal contaminants (such as $\mathrm{Cd}$ and $\mathrm{Pb}$ ). Anthropogenic activities associated with agriculture, industry, vehicular traffic and mining resulted in the incorporation of increased amounts of such metals from both groups. They are believed to be easily accumulated in the topsoil, resulting in the potential of toxicity to living organisms (Alloway, 2013).

The soil solution concentration, and hence the bioavailability and toxicity of these metals, are controlled mostly by sorption-desorption reactions on the surface of the soil colloidal materials. Batch equilibrium techniques are primarily used to study the retention of metals in soils. In this case, the sorption data can be described by sorption curves and their analysis provides information about the retention capacity and the strength with which the sorbate is held on to the soil (Morera et al., 2001). Quantification of sorption capacity of soils should play a very important role in all discussions related to soil contaminant loadings, buffering capacities and critical loads of potentially toxic materials (Fontes \& Gomes, 2003).

Metals' sorption by soils depends on several factors such as the nature of organic and mineral soil constituents, the composition of the soil solution as well as the soil $\mathrm{pH}$ and Eh (McLaughlin et al., 2000). As long as these latter factors may show significant temporal variation even within a very short time (Szalai, 2008), soil mineral components can be regarded as relatively stable soil characteristics (Turpault et al., 2008). 
A general observation is that soil metal sorption increases with decreasing particle size (Madzhieva et al., 2014). This has been attributed to the enrichment of soil components with high surface area, like clay minerals, Fe-Mn oxides and organic matter, in the small particle size fractions of soils (Sparks, 2002). However, significantly different sorption behavior of metals (for $\mathrm{Pb}$ and $\mathrm{Cu}$ ) was found by Sipos (2010) when sorption characteristics of bulk soils and their clay fractions were compared. Enrichment in the amount of swelling clay minerals in clay fractions affected the sorption of $\mathrm{Cu}$ in much higher degree than for $\mathrm{Pb}$, although their sorption behavior in the bulk soils suggested the higher affinity of $\mathrm{Pb}$ for clay surfaces. This suggests that evaluation of the effect of soil components on metals' sorption in soils is a highly complicated task due to the large heterogeneity of the major soil components affecting this process.

Among clay minerals, the highest sorption capacity for metals has been observed for smectites (Uddin, 2017). It is also supported by several studies that soils with significant smectite content show higher sorption capacities for metals than those containing other clay mineral species (Serrano et al., 2005). Although there are many studies on the sorption of heavy metals by soils in general, their clay mineralogy is rarely characterized in details. Additionally, comparative studies on sorption capacities of soils characterized by a single clay mineral species dominantly are scarce, although they are expected to reduce the heterogeneity of parameters to evaluate. The aim of this study was to fill this gap through the study of $\mathrm{Cd}, \mathrm{Cu}, \mathrm{Pb}$ and $\mathrm{Zn}$ sorption capacities of six soils with highly variable properties except clay mineralogy which is dominated by smectite.

\section{MATERIALS AND METHODS}

Three acidic and three alkaline soil samples were selected for the sorption experiments based on the OECD Guideline No. 106 (2000). Accordingly, the studied soils show high variation in their $\mathrm{pH}$, organic carbon and clay content, as well as in their texture. The common mineralogical feature is that their dominant clay mineral species is smectite, except sample S3 where it is chlorite. The major physico-chemical properties of the soils are summarized in Table 1.

Soil $\mathrm{pH}$ was analysed in $0.1 \mathrm{M} \mathrm{CaCl}_{2}$ solution using 1:2.5 solid:solution ratio by a Radelkis OP 211 analyser. Total organic carbon content was analysed by a Tekmar-Dohrmann Apollo 9000N TOC instrument. The BET surface area was determined using a Quantochrome Autosorb-1-MPV automated gas sorption system using $\mathrm{N}_{2}$ gas. The cation exchange capacity (CEC) of the samples was determined using the hexamine-cobalt-trichloride solution (ISO 23470:007 standard method). Particle size distribution of the samples was analysed by a Fritsch Analysette Microtech A22 laser diffraction instrument.

Clay minerals were identified from the clay fractions of bulk samples by XRD analyses (Philips PW 1729) obtained from parallel-oriented specimens. Separation of the clay fractions were performed by sedimentation in aqueous suspension. The following diagnostic treatments were carried out for all of the samples: ethylene glycol solvation at $60^{\circ} \mathrm{C}$ overnight, $\mathrm{Mg}$ saturation followed by glycerol solvation at $95^{\circ} \mathrm{C}$ overnight, $\mathrm{K}$ saturation, heating on 350 and $550^{\circ} \mathrm{C}$ for 2 hours.

Total $\mathrm{Fe}, \mathrm{Cd}, \mathrm{Cu}, \mathrm{Pb}$ and $\mathrm{Zn}$ content of the samples were determined by ICP-MS (Perkin Elmer Elan 9000) analyses after 4-acid digestion as follows. A $0.25 \mathrm{~g}$ split of soil was heated in $\mathrm{HNO}_{3}-\mathrm{HClO}_{4}-\mathrm{HF}$ to fuming and taken to dryness. The residue was dissolved in $\mathrm{HCl}$. The quality of the analyses has been checked by the study of a standard reference material (OREAS45E). Analysed and expected concentrations are 4.63 and $4.45 \%$ for $\mathrm{Fe}, 0.18$ and $0.20 \mathrm{mg} / \mathrm{kg}$ for $\mathrm{Cd}, 52$ and $43 \mathrm{mg} / \mathrm{kg}$ for $\mathrm{Cu}, 18$ and $22 \mathrm{mg} / \mathrm{kg}$ for $\mathrm{Pb}$, 47 and $44 \mathrm{mg} / \mathrm{kg}$ for Zn. Free iron oxide content of the samples were determined by dithionite-citratebicarbonate dissolution after the method of Mehra and Jackson (1960). Extracted iron concentration was analysed by atomic absorption spectrometry (Perkin Elmer AAnalyst 300).

Table 1. The major physico-chemical properties of the studied soil samples.

\begin{tabular}{|l|l|l|c|c|c|c|c|c|c|}
\hline Sample & Soil type & Horizon & $\mathrm{pH}$ & TOC & BET-surface & CEC & $\mathrm{Fe}_{\mathrm{t}}$ & $\mathrm{Fe}_{\mathrm{d}}$ & $\mathrm{Clay}$ \\
\hline & & & $\left(\mathrm{CaCl}_{2}\right)$ & $(\%)$ & $\left(\mathrm{m}^{2} / \mathrm{g}\right)$ & $(\mathrm{cmol} / \mathrm{kg})$ & $(\%)$ & $(\%)$ & $(\%)$ \\
\hline S1 & Luvisol & A1 & 4.61 & 4.99 & 10 & 14.6 & 3.03 & 1.14 & 9.0 \\
\hline S2 & Luvisol & B1 & 4.28 & 0.54 & 33 & 14.0 & 4.03 & 1.54 & 19.2 \\
\hline S3 & Luvisol & A1 & 3.31 & 3.74 & 3.0 & 4.8 & 0.91 & 0.34 & 5.5 \\
\hline C1 & Phaeozem & A2 & 7.65 & 3.69 & 27 & 20.9 & 4.52 & 2.84 & 37.3 \\
\hline C2 & Phaeozem & A & 8.10 & 2.72 & 13 & 15.8 & 1.21 & 0.23 & 14.9 \\
\hline C3 & Phaeozem & C2 & 7.93 & 0.34 & 29 & 12.3 & 4.45 & 2.69 & 18.1 \\
\hline
\end{tabular}

TOC = total organic carbon, $\mathrm{CEC}=$ cation exchange capacity, $\mathrm{t}=$ total element content, $\mathrm{d}=$ dithionite extractable element content. 
Single element and competitive batch sorption experiments were carried out in duplicates. In polypropylene centrifuge tubes of $50 \mathrm{ml}, 1 \mathrm{~g}$ soil sample was mixed with $30 \mathrm{~mL}$ solution containing various concentrations $(0.1,0.2,0.5,1,2,5$ and 10 $\mathrm{mmol} / \mathrm{l}$ ) of $\mathrm{Cd}, \mathrm{Cu}, \mathrm{Pb}$ and $\mathrm{Zn}$ in form of nitrates and $0.01 \mathrm{M} \mathrm{Ca}\left(\mathrm{NO}_{3}\right)_{2}$ as background electrolyte. The initial $\mathrm{pH}$ of each solution was set to 5.5 to avoid metal hydroxide precipitation (Vidal et al., 2009). Soil samples were equilibrated with the solutions by shaking them for 24 hours at $22^{\circ} \mathrm{C}$. After that, they were centrifuged at $4000 \mathrm{rpm}$ for 20 minutes and the supernatant was filtered and analysed for concentrations of the studied metals.

Concentrations of $\mathrm{Cd}, \mathrm{Cu}, \mathrm{Pb}$ and $\mathrm{Zn}$ in the equilibrated solutions of the sorption experiments were analyses by atomic absorption spectrometry (Perkin Elmer AAnalyst 300). The relative standard deviations of the duplicate analyses are less than 5\% for each metal at equilibrium concentrations above $100 \mathrm{mg} / \mathrm{l}$ and never reached $10 \%$ for $\mathrm{Cd}$ and $\mathrm{Zn}$ at lower concentrations. For $\mathrm{Cu}$ and $\mathrm{Pb}$, it was always less than $10 \%$ and $30 \%$ at equilibrium concentrations below 100 and $0.1 \mathrm{mg} / \mathrm{l}$, respectively. The amount of metals adsorbed by the soil samples were calculated using the equation (1):

$$
Q e=\frac{(C i-C e) \cdot V}{W}(1)
$$

where Qe is the sorbed metal amount per unit weight of the soil $(\mathrm{mmol} / \mathrm{kg})$, Ce is the equilibrium metal concentration in the solution $(\mathrm{mmol} / \mathrm{l}), \mathrm{Ci}$ is the initial metal concentration in the solution $(\mathrm{mmol} / \mathrm{l})$, $\mathrm{V}$ is the volume of the solution ( $\mathrm{ml}$ ) and $\mathrm{W}$ is the weight of the air-dried soil (g). The Langmuir isotherm equation was used to describe the adsorption of the studied metals from the solution onto the studied soils samples. Its non-linear form can be expressed as

$$
Q e=\frac{Q \max \cdot b \cdot C e}{1+b \cdot C e}(2)
$$

where Qmax is the maximum sorption capacity of the solid $(\mathrm{mmol} / \mathrm{kg}$ ) and $\mathrm{b}$ represents the Langmuir bonding term related to the adsorption energy $(\mathrm{l} / \mathrm{kg})$. Isotherm model parameters were obtained using nonlinear regression analysis. The coefficient of determination $\left(\mathrm{R}^{2}\right)$ was used to evaluate the applicability of the Langmuir isotherm to the experimental data by a trial-and-error procedure with the Solver add-in function of Microsoft Excel software.

The relative percentage change or relative sorption capacity (RSC) was also used to compare the metal sorption capacity of the samples. The RSC value can be calculated by taking the percentile ratio of the equilibrium and initial metal concentrations
(Xiong et al., 2005).

Major physico-chemical properties of the soil samples as well as the Qmax and RSC values as characteristic parameters of metal sorption in soils were related by statistical analysis. Hierarchical cluster analysis using Ward's method and squared Eucledian distance was performed using the MS Excel add-in Multibase package (Numerical Dynamics, Japan).

\section{RESULTS}

\subsection{Sorption curve evaluation}

The shape of the sorption curve may provide information about the major immobilization processes. Large differences were found between the sorption curves of the studied metals in acidic and alkaline soils (Fig. 1). According to the classification of Giles et al. (1974), the most frequent curve type is the L1 in the acidic soils for each studied metal. This means that no saturation plateau is reached for the Langmuir monolayer in most of these cases. However, $\mathrm{Cu}$ in the samples with lower clay content (S1 and $\mathrm{S} 3$ ) and $\mathrm{Pb}$ in the sample with the highest clay content (S2) reach the saturation.

On the other hand, further exceptions are $\mathrm{Cd}$ and $\mathrm{Zn}$ in the sample S3 where they showed C type sorption curve suggesting low affinity to this sample. Moreover, sorption curves of $\mathrm{Zn}$ can be characterized by a maximum (Lmax) in competitive situation in the samples S1 and S3 suggesting the increasing role of competition with increasing metal concentrations. In the alkaline samples, however, $\mathrm{H} 1$ type sorption curves were found for each metal in single element situation, with complete retention for $\mathrm{Cu}$ and $\mathrm{Pb}$ in the whole range of initial metal concentrations. In competitive situation, also $\mathrm{H}$ type curves were observed as shown by the RSC values of $100 \%$ at low initial metal concentrations. Exception of $\mathrm{Pb}$, each studied metals showed also saturation in competitive situation in these samples. This is completed by a maximum for $\mathrm{Cd}$ in the sample with lowest clay content (C2) and for $\mathrm{Zn}$ in all alkaline samples which can be related to both increasing competition and the decrease of solution $\mathrm{pH}$ as sorption progresses.

Plotting the relative sorption capacity (RSC) in the function of initial metal concentrations provides also a useful tool to compare the sorption behaviour of the metals (Fig. 2). The RSC values decreased as initial metal concentration increased in most of the cases. However, there were found large differences among the behaviour of the studied metals which was significantly affected both by the competitive situation and the soil properties. 


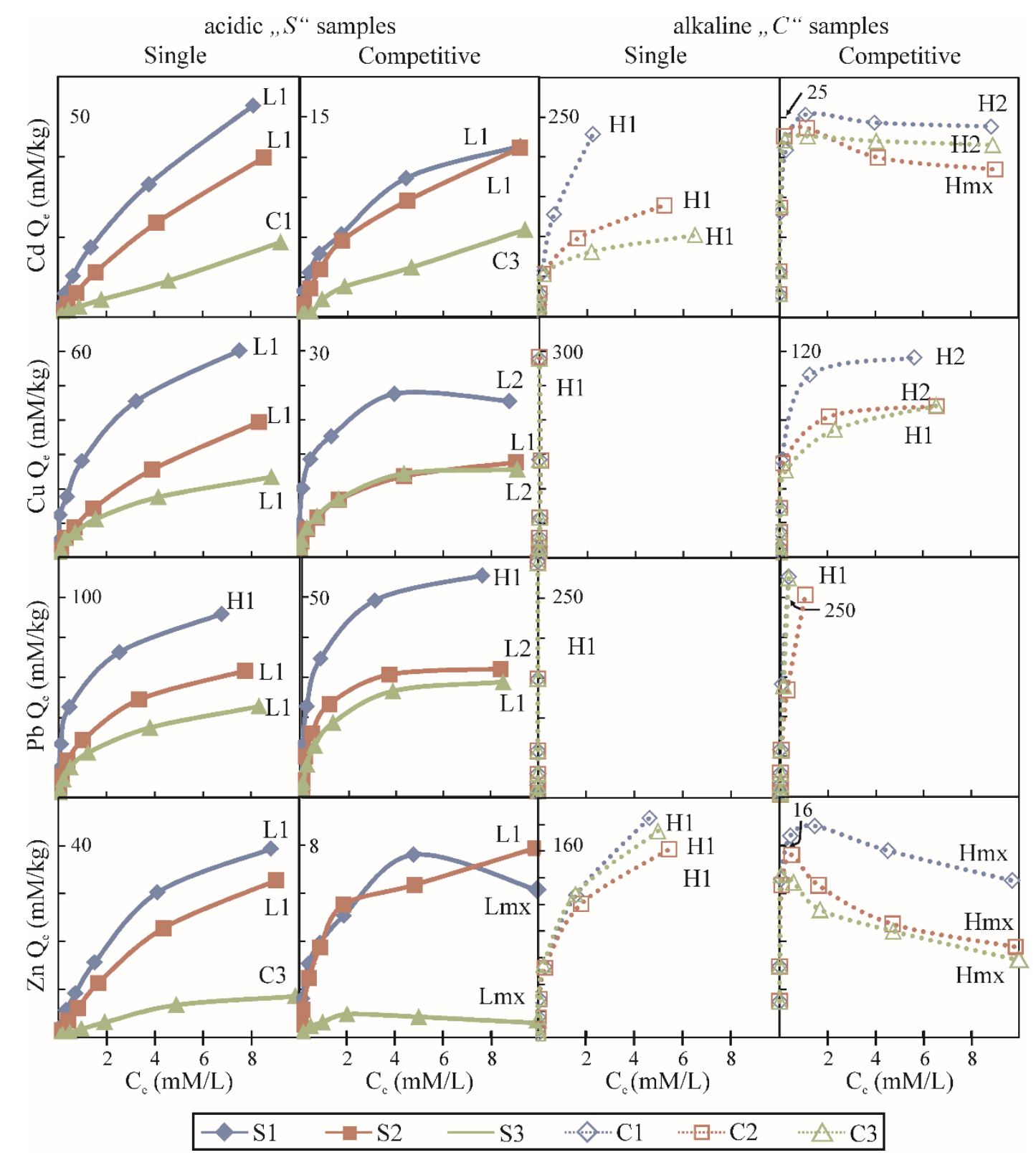

Figure 1. Results of the sorption experiments as shown by sorption curves. Ce = equilibrium metal concentrations in the solution, Qe = equilibrium sorbed metal amounts on soils.

The most conspicuous phenomenon was the higher relative sorption capacity of soils for $\mathrm{Pb}$ and $\mathrm{Cu}$ than for $\mathrm{Cd}$ and $\mathrm{Zn}$. This difference is primarily characteristic of the low initial metal concentrations in the acidic samples and it decreases as the initial metal concentration increases. In the alkaline samples, however, this difference increases with the initial metal concentrations and even constant RSC values (around $100 \%$ ) could be found for $\mathrm{Cu}$ and $\mathrm{Pb}$ in for the whole metal concentration range at single element conditions.

In the acidic samples, the RSC values decreases in the order of S1, S2 and S3 at single element conditions for each metals. In competition, however, these differences disappear at the highest initial metal concentrations for $\mathrm{Cd}$ and $\mathrm{Zn}$, and this is the case for $\mathrm{Pb}$ and $\mathrm{Cu}$ for the samples S2 and S3. The difference between the behaviour of metals in single element and competitive situations is more expressed in the alkaline samples. The competitive situation affects the sorption of metals more significantly which is shown by the higher decrease of the RSC values.

Additionally, differences cannot be made among the sorption behaviour of $\mathrm{Cu}$ and $\mathrm{Pb}$ in the alkaline samples at single element and that of $\mathrm{Cd}$ and $\mathrm{Zn}$ at competitive situation. The previous one can be related to the fact that $\mathrm{Cu}$ and $\mathrm{Pb}$ show complete retention at the whole initial metal concentration range in single element situation; however, competition results in differentiation of their sorption in the alkaline samples with the highest affinity for the sample with highest TOC and clay content (C1) for $\mathrm{Cu}$ and for those with highest $\mathrm{pH}$ (C2 and $\mathrm{C} 3$ ) for $\mathrm{Pb}$. 


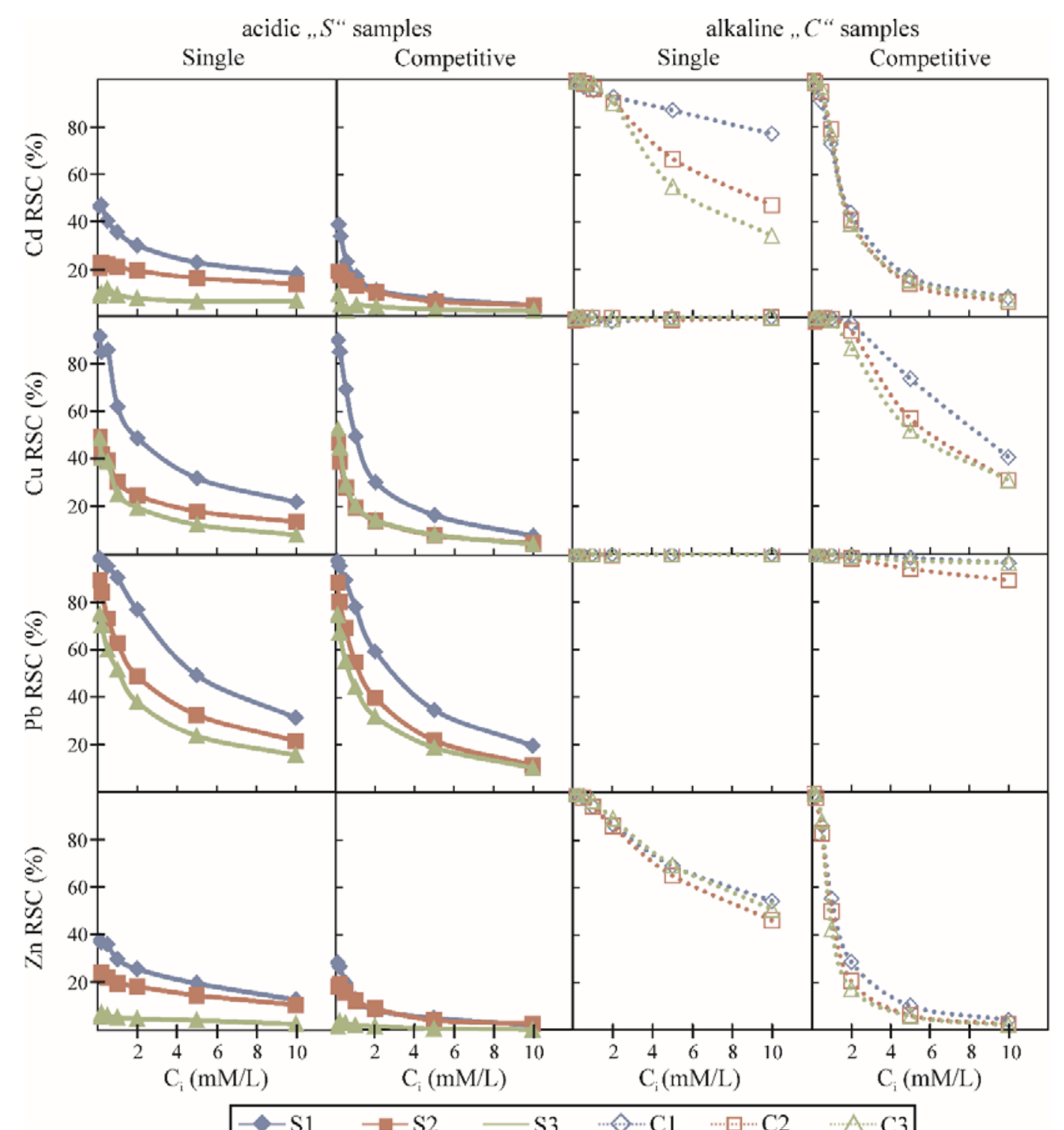

Figure 2. Results of the sorption experiments as shown by the relative sorption capacities. $\mathrm{Ci}=$ initial metal concentrations, RSC = relative sorption capacity.

On the contrary, competition resulted in very similar sorption behaviour for $\mathrm{Cd}$ and $\mathrm{Zn}$ in all three alkaline samples, whereas large and slight differences were found for $\mathrm{Cd}$ and $\mathrm{Zn}$, respectively, in single element situation for these samples. Highest RSC values were found for $\mathrm{Cd}$ in the sample $\mathrm{C} 1$ followed by the samples $\mathrm{C} 2$ and $\mathrm{C} 3$ which may be related to their decreasing TOC content. For Zn, however, RSC values decrease in the order of C1, C3 and C2 suggesting close relation to the clay content and $\mathrm{pH}$ of the samples.

$\mathrm{As} \mathrm{Pb}$ and $\mathrm{Cu}$ show higher decrease in the RSC values with increasing initial metal concentrations than Cd and Zn, the RSC values at the highest initial metal concentrations can be very similar primarily for $\mathrm{Cu}$ and $\mathrm{Cd}$ although their RSC values show large differences at lower initial metal concentrations. This is primarily characteristic of the acidic soils samples both at single element and competitive situations. This phenomenon may result in similar Langmuir Qmax values for these two metals in these cases although $\mathrm{Cd}$ exhibits lower affinity to soils than $\mathrm{Cu}$ obviously.

\subsection{Fit of the Langmuir isotherms to the experimental data}

The fit of the Langmuir isotherms to the experimental data points are generally excellent, the $\mathrm{R}^{2}$ value is higher than 0.93 in the two-thirds of the cases (Table 2). In the case of certain sorption curve type, however the goodness of fit declines to varying degree. These are the curves showing a maximum ( $\mathrm{Zn}$ in the samples S3, C2 and C3) where lower fits were observed although the $\mathrm{R}^{2}$ values are still higher than 0.7 . 
Table 2. Results of the sorption curve evaluation.

\begin{tabular}{|c|c|c|c|c|c|c|c|c|c|c|c|}
\hline \multirow[t]{2}{*}{ Sample } & \multirow[t]{2}{*}{ Metal } & \multicolumn{5}{|c|}{ Single element } & \multicolumn{5}{|c|}{ Competitive } \\
\hline & & $\mathrm{Q}_{\max }$ & $\mathrm{b}$ & $\mathrm{R}^{2}$ & $\mathrm{RSC}_{\mathrm{av}}$ & $\begin{array}{l}\text { Curve } \\
\text { type }\end{array}$ & $\mathrm{Q}_{\max }$ & $\mathrm{b}$ & $\mathrm{R}^{2}$ & $\mathrm{RSC}_{\mathrm{av}}$ & $\begin{array}{c}\text { Curve } \\
\text { type }\end{array}$ \\
\hline \multirow[t]{4}{*}{ S1 } & $\mathrm{Cd}$ & 79 & 0.23 & 0.99 & 34 & L1 & 14 & 0.80 & 0.98 & 19 & L1 \\
\hline & $\mathrm{Cu}$ & 64 & 1.10 & 0.97 & 61 & L1 & 22 & 7.4 & 0.96 & 50 & L2 \\
\hline & $\mathrm{Pb}$ & 82 & 5.5 & 0.97 & 77 & $\mathrm{H} 1$ & 53 & 6.6 & 0.97 & 68 & L1 \\
\hline & $\mathrm{Zn}$ & 53 & 0.31 & 1.00 & 28 & L1 & 7.4 & 1.6 & 0.94 & 15 & Lmx \\
\hline \multirow[t]{4}{*}{$\mathrm{S} 2$} & $\mathrm{Cd}$ & 87 & 0.11 & 1.00 & 19 & L1 & 16 & 0.36 & 0.99 & 12 & L1 \\
\hline & $\mathrm{Cu}$ & 55 & 0.30 & 0.99 & 31 & L1 & 15 & 1.1 & 0.99 & 23 & L1 \\
\hline & $\mathrm{Pb}$ & 69 & 1.09 & 0.99 & 59 & L1 & 33 & 3.3 & 0.99 & 52 & L2 \\
\hline & $\mathrm{Zn}$ & 53 & 0.18 & 1.00 & 19 & L1 & 8.4 & 0.93 & 0.99 & 12 & L1 \\
\hline \multirow[t]{4}{*}{ S3 } & $\mathrm{Cd}$ & 87 & 0.05 & 0.99 & 8 & C1 & 13 & 0.13 & 0.99 & 4 & C3 \\
\hline & $\mathrm{Cu}$ & 25 & 0.72 & 0.98 & 28 & L1 & 13 & 1.7 & 0.98 & 25 & L2 \\
\hline & $\mathrm{Pb}$ & 50 & 0.96 & 0.99 & 48 & L1 & 30 & 1.7 & 0.99 & 43 & L2 \\
\hline & $\mathrm{Zn}$ & 14 & 0.16 & 0.99 & 5 & C3 & 0.9 & 1.9 & 0.78 & 2 & Lmx \\
\hline \multirow[t]{4}{*}{ C1 } & $\mathrm{Cd}$ & 286 & 1.7 & 0.99 & 93 & H1 & 24 & 45 & 0.98 & 61 & $\mathrm{H} 2$ \\
\hline & $\mathrm{Cu}$ & 711 & 233 & 0.52 & 99 & H1 & 108 & 33 & 0.97 & 87 & H2 \\
\hline & $\mathrm{Pb}$ & 395 & 611 & 0.58 & 100 & $\mathrm{H} 1$ & 304 & 1705 & 0.98 & 99 & $\mathrm{H} 1$ \\
\hline & $\mathrm{Zn}$ & 175 & 1.9 & 0.97 & 86 & H1 & 15 & 186 & 0.93 & 54 & $\mathrm{Hmx}$ \\
\hline \multirow[t]{4}{*}{ C2 } & $\mathrm{Cd}$ & 127 & 5.1 & 0.96 & 85 & H1 & 21 & 120 & 0.94 & 62 & $\mathrm{Hmx}$ \\
\hline & $\mathrm{Cu}$ & 778 & 55 & 0.54 & 99 & H1 & 83 & 31 & 0.97 & 82 & $\mathrm{H} 2$ \\
\hline & $\mathrm{Pb}$ & 454 & 315 & 0.62 & 100 & H1 & 285 & 6.0 & 0.97 & 97 & $\mathrm{H} 1$ \\
\hline & $\mathrm{Zn}$ & 134 & 3.1 & 0.97 & 84 & H1 & 11 & 306 & 0.73 & 51 & $\mathrm{Hmx}$ \\
\hline \multirow[t]{4}{*}{ C3 } & $\mathrm{Cd}$ & 87 & 22 & 0.95 & 82 & H1 & 22 & 175 & 0.99 & 62 & H2 \\
\hline & $\mathrm{Cu}$ & 700 & 1492 & 0.51 & 100 & $\mathrm{H} 1$ & 75 & 39 & 0.93 & 81 & $\mathrm{H} 1$ \\
\hline & $\mathrm{Pb}$ & 506 & 343 & 0.73 & 100 & H1 & 385 & 8.5 & 0.97 & 99 & H1 \\
\hline & $\mathrm{Zn}$ & 147 & 3.5 & 0.96 & 86 & H1 & 10 & 829 & 0.70 & 51 & $\mathrm{Hmx}$ \\
\hline
\end{tabular}

Qmax = Langmuir maximum monolayer coverage (mmol/kg), b = Langmuir bonding term (l/kg), RSCav = average relative sorption capacity (\%).

For curves which show complete sorption in the whole initial concentration range (for single element $\mathrm{Pb}$ and $\mathrm{Cu}$ sorption in alkaline samples) the goodness of fit shows much higher decline resulting $\mathrm{R}^{2}$ values between $0.51-0.73$. This can be due to the fact that small fluctuations (equal to a few hundredth percent of the sorbed amounts) in the experimental data may significantly affect the goodness of fit of the practically vertical sorption curve. Such a small fluctuations in the experimental values are within the standard deviation of the analyses. Consequently, sorption curves for the acidic samples show generally good fit to the Langmuir isotherms, whereas precipitation of certain metals in the alkaline samples results in a significant decline of the fit and in a lowering of the reliability of the estimated Langmuir parameters. Additionally, the fit is generally better in competitive than in single element situations which can be related to the lower importance of precipitation although curves with a maximum are much more characteristic in this case. Sorption curves of metals which are not affected either by precipitation or by competition significantly show generally very good fit to the Langmuir isotherms.
3.3. Langmuir maximum sorption and relative sorption capacities

The maximum monolayer coverage (Qmax) values calculated from the Langmuir curves fitted to the experimental data and the average relative sorption capacity values (RSCav) are summarized in Table 2. In the alkaline samples, $\mathrm{Pb}$ and $\mathrm{Cu}$ often show a vertical sorption curve. The calculated Qmax values show very high sorption capacities in these cases and the reliability of such data is lower as mentioned above, although they suggest very high immobilization still correctly. On the other hand, Qmax values may be slightly underestimated when calculated from fitting to data forming curves with a maximum. This is the case for $\mathrm{Zn}$ and $\mathrm{Cd}$ in certain samples as well as in competitive situation. Additionally, Cd generally shows much lower decrease in its relative sorption capacity when compared to $\mathrm{Cu}$ (and $\mathrm{Pb}$ ) at higher initial metal concentrations resulting in a similar or higher Qmax value for it than to $\mathrm{Cu}$, although $\mathrm{Cd}$ can be characterized by a much lower sorption than $\mathrm{Cu}$ in a wide initial concentration range as shown by its RSC 
values. Based on the above, exact Qmax values provide misleading information sometimes on the rate of sorption in the studied samples. Thus, Qmax and RSCav values are suggested to be used together for the evaluation of the sorption properties of soils (Xiong et al., 2005), as the latter ones directly show the metal amounts immobilized by the given soil sample. Otherwise, the Qmax and RSCav values show strong linear correlation both in single element $\left(\mathrm{R}^{2}=0.70\right)$ and competitive situations $\left(\mathrm{R}^{2}=0.73\right)$. However, it can be characterized by a significant decline for the acidic samples at single element situation $\left(\mathrm{R}^{2}=0.31\right)$ which can be due to the overestimation of the Qmax data for Cd as compared to its RSCav values. This observation is also shown up in the affinity sequences of the studied metals. If the RSCav values are studied, the $\mathrm{Pb}>\mathrm{Cu}>\mathrm{Cd}>\mathrm{Zn}$ affinity sequence can be defined, except for sample C3 (the one with the lowest TOC content) at single element conditions, where $\mathrm{Zn}$ (86\%) show higher RSCav values than Cd (82\%). On the contrary, affinity sequences based on the Qmax values show significantly different features as Cd mostly exhibit higher Qmax values than $\mathrm{Cu}$ in the acidic samples both in single element and competitive situation (except in sample S1 with the highest TOC content at competitive situation), and it can be characterized by the highest Qmax values in the most acidic samples (S2 and S3) at single element situation. Additionally, $\mathrm{Cu}$ showed slightly higher $\mathrm{Qmax}$ values than $\mathrm{Pb}$ in the alkaline samples, and also Zn showed higher values than $\mathrm{Cd}$ in the most alkaline (C2 and C3) samples at single element situation.

As it was expected, higher metal sorption was found at single element than at competitive situation. The lowest difference was found for $\mathrm{Pb}$, where $1.6 \pm$ 0.3-times higher Qmax values were found on average at single element than at competitive situation. It is followed by $\mathrm{Cu}(5.6 \pm 3.3)$, Cd $(6.6 \pm 2.8)$ and $\mathrm{Zn}$ (11.2 \pm 3.9$)$. Lower differences but the same sequence was found when the RSCav values were compared: $1.1 \pm 0.1$ for $\mathrm{Pb}, 1.2 \pm 0.1$ for $\mathrm{Cu}, 1.6 \pm 0.2$ for $\mathrm{Cd}$, and $1.9 \pm 0.5$ for $\mathrm{Zn}$. No significant differences were observed between the acidic and alkaline samples in this point of view, except for $\mathrm{Cu}$ which showed significantly higher ratios in the alkaline $(8.4 \pm 2.0)$ than in the acidic samples $(2.8 \pm 0.8)$. Also slight differences among the studied samples for $\mathrm{Cd}$ and $\mathrm{Zn}$ were found from this point of view, but this could not be related to the soil $\mathrm{pH}$. The highest difference for $\mathrm{Zn}$ was found in the most acidic sample (S3) but it was also similarly high in all the alkaline samples. On the other hand, Cd showed similar ratios in most of the samples, except in the one with the highest CEC and Fed values (C1) where this ratio was twice as much as in the other samples. Finally, $\mathrm{Pb}$ exhibited very similar values in each studied sample.

\subsection{Relationship between the sorption capacities and soil properties}

As it was expected, the Qmax and RSCav values were generally higher in the alkaline than in the acidic soil samples for each metal. The RSCav values are 5-6-times higher for $\mathrm{Zn}$ and 4-5-times higher for $\mathrm{Cd}$ in the alkaline as compared to the acidic soils. On the contrary, these values are only 2.5 and 1.6-1.8times higher for $\mathrm{Cu}$ and $\mathrm{Pb}$, respectively. These data suggest a more marked increase in the sorption of $\mathrm{Cd}$ and $\mathrm{Zn}$ in alkaline soils when compared to $\mathrm{Cu}$ and $\mathrm{Pb}$. This observation was also supported by the correlation analysis. A very close linear relationship was found between the soil $\mathrm{pH}$ and both the Qmax $\left(\mathrm{R}^{2}>0.83\right)$ and RSCav $\left(\mathrm{R}^{2}>0.96\right)$ values, except for the Qmax of $\mathrm{Cd}$ at single element situation. Also close linear relationship was found between the sorption capacities and CEC $\left(\mathrm{R}^{2}>0.63\right)$ and clay content $\left(\mathrm{R}^{2}>0.60\right)$ of the samples. Exceptions are Qmax values for $\mathrm{Pb}$ and RSCav values for $\mathrm{Cu}$, where lower relationship was found to both variable and clay content, respectively. All other studied variables (TOC, BET-surface area, $\mathrm{Fe}_{\mathrm{d}}, \mathrm{Fe}_{\mathrm{t}}$ ) did not show linear relationship either with Qmax or with RSCav values.

These results show good agreement to that of the cluster analyses (Fig. 3). These latter ones were carried out on the whole data set and also separately on the data from single element and competitive experiments. Due to the small number of data and the complexity of potential relationships among soil properties and sorption capacities, slight contradictions could be observed only. When the Qmax values are compared to the soil properties, Cd and $\mathrm{Zn}$ showed closer relationship to all the studied soil properties than $\mathrm{Cu}$ and $\mathrm{Pb}$, which is more pronounced at competitive situation. However, results do not allow to do clear differentiation among soil properties with respect to their relationship to Qmax values of Cd and/or Zn.

On the other hand, when the RSCav values are related to the soil properties, lower similarity between the studied variables could be found. The closer relationship of the RSCav values of $\mathrm{Cd}$ and $\mathrm{Zn}$ than that of $\mathrm{Cu}$ and $\mathrm{Pb}$ to the soil properties at competitive situation could be also observed in this case.

Cluster analyses also supported the observation on the different sorption behaviour of the metal-pairs of $\mathrm{Cd}-\mathrm{Zn}$ and $\mathrm{Cu}-\mathrm{Pb}$ in the studied soils. Moreover, $\mathrm{Cd}$ and $\mathrm{Zn}$ showed higher similarity to each other in their sorption properties than $\mathrm{Cu}$ and $\mathrm{Pb}$. 

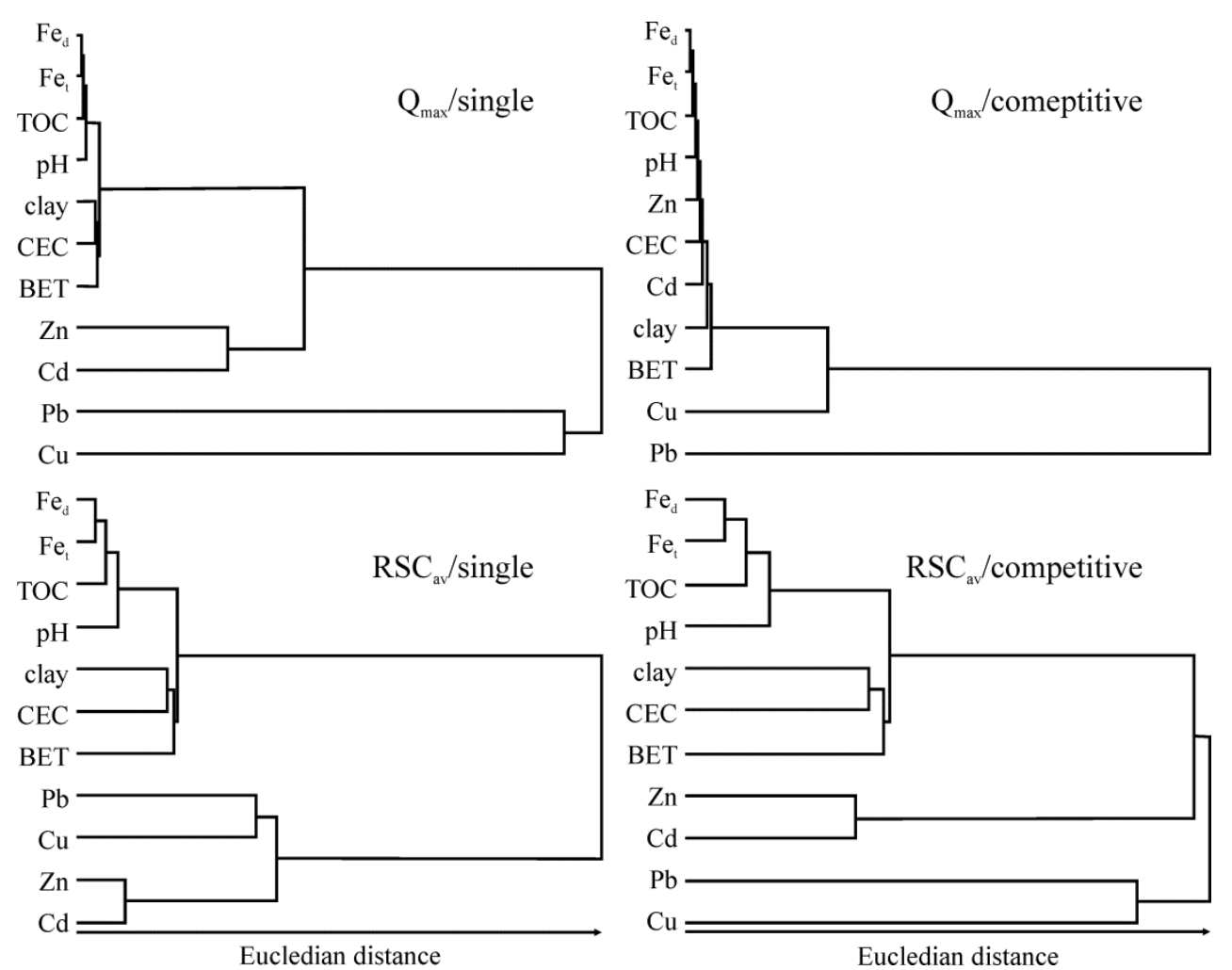

Figure 3. Results of cluster analysis showing the relationship between the sorption capacities and soil properties for single element and competitive situations.

\section{DISCUSSION}

The generally observed phenomenon that $\mathrm{Pb}$ and $\mathrm{Cu}$ can be characterized higher sorption than $\mathrm{Cd}$ and $\mathrm{Zn}$ was also found in the studied soils. The affinity sequence of the studied metals is as follows: $\mathrm{Pb}>\mathrm{Cu}>\mathrm{Cd}>\mathrm{Zn}$. It is primarily explained by the fact that sorption of the metals may depend on both electrostatic forces and on covalent bonding with available surfaces in the soil. Results of Sangiumsak \& Punrattanasin, (2014) showed that high and quick leaching of metals with lower sorption (like that of Zn) suggests immobilization by non-specific adsorption whereas those with higher sorption (like $\mathrm{Cu}$ ) are immobilized rather by specific adsorption. This behavior of metals can be related to their certain chemical properties like electronegativity, hydrolysis constants, ionic radius etc. (Zhang et al., 2012). These results are also in harmony with that of Baghenejad et al., (2016) who found that large amount of added Cd and Zn to soils may remain as soluble forms in the soil solution even at alkaline conditions that can intensify their uptake by plant roots or their leaching from soil profile and entrance to groundwater posing higher environmental risk than caused by $\mathrm{Pb}$ or $\mathrm{Cu}$. In the sample with the lowest TOC content, however, Zn showed slightly higher affinity than Cd. Low TOC content in soil is expected to inhibit the sorption of $\mathrm{Zn}$ rather than $\mathrm{Cd}$ as suggested by several results (e.g. Wong et al., 2007). This sample, however, can be also characterized by relatively high smectite and Fed content and also alkaline $\mathrm{pH}$ causing favourable sorption for $\mathrm{Zn}$ than for $\mathrm{Cd}$, primarily due to their smectite content and secondary to the potential presence of iron-oxyhydroxide coating on the soil (clay) particles (Helios-Rybicka \& Wojcik, 2012).

For the correct characterization of the sorption capacity of a given soil, the Qmax and RSC values must be evaluated together. As long as Qmax values are significantly affected by the isotherm shape, RSC values show the rate of the sorption directly (Xiong et al., 2005). This may result in similar Qmax values for metals with different sorption curve types, although their RSC values may show large differences. This is, however, cannot be related to the goodness of fit of the Langmuir isotherms to the experimental data, rather to the effect of sorption process or conditions (like precipitation and competition) on the isotherm type. That is why exact Qmax values cannot be used to characterize the sorption capacity of a soil exclusively, although they show the trends of the sorption correctly. An example for that case is that of Cd with type 1 isotherm (no saturation), which may exhibit higher Qmax values than $\mathrm{Cu}$ with type 2 isotherm (close to saturation) in the acidic soils, although the relative sorption capacity of the latter metal is generally higher than that of the previous 
one, except at the highest concentration level where similar rates were found. Vidal et al., (2009) also found that $\mathrm{Cd}$ is a competitive metal for Cu only if the initial concentration the previous metal is high enough, and for scenarios with a decrease in site selectivity for the target metal. This latter one is the case also for our acidic samples where the equilibrium $\mathrm{pH}$ values at the highest initial metal concentrations are around 3 and 4 suggesting low site selectivity for cationic metals (Violante et al., 2008). Contrarily, in the sample with highest TOC, $\mathrm{Cu}$ showed higher Qmax value than Cd in spite of the low $\mathrm{pH}$ showing the higher affinity of $\mathrm{Cu}$ to organic matter at acidic conditions. This is in harmony with the observations of Covelo et al., (2007) who found that $\mathrm{Cu}$ (and also $\mathrm{Pb}$ ) shows higher sorption in soils with high organic matter content primarily due to the formation of metal complexes with organic matter whereas $\mathrm{Cd}$ is retained in exchangeable form and is more readily available.

The sorption behavior of metals was found to be expressed also by the effect of competition on their sorption capacities. Metals with higher sorption were found to be affected by the competition at lower rate than those with low sorption. They showed the inverse sequence as in case of their sorption affinity, e.g. the effect of competition decreased as follows: $\mathrm{Zn}>\mathrm{Cd}>\mathrm{Cu}>\mathrm{Pb}$. Vidal et al., (2009) studied the effect of competition on the sorption of metals pairs of the same elements as in our case. They found that the effect of competition was more evident for those metals which sorption is controlled by both inner (chemical bond) and outersphere (ion pair) mechanisms (like $\mathrm{Cd}$ and $\mathrm{Zn}$ ). Although the effect of $\mathrm{pH}$ on that of the competition could be expected, this was the case only for $\mathrm{Cu}$. Here, competition exhibited higher effect on the sorption of $\mathrm{Cu}$ at alkaline than at acidic soil conditions. This can be related to the appearance of precipitation as immobilization process at alkaline conditions, which is also a competitive process when free $\mathrm{Pb}$ is also available to form carbonates. Cao et al. (2003) showed that Pb-carbonate may be precipitated in neutral and alkaline soils when free carbonate is available and are stable in the range of $\mathrm{pH}$ 6-10. In contrast, Cu-carbonate precipitation can be also expected both in neutral and alkaline soils (Pozinovsky et al., 2007), but the chance of its formation decreases significantly with the increase of soil organic matter content (Rutkowska et al., 2013). This metal was found to be bound to soil organic matter also in highly calcareous soils dominantly (Jalali \& Khanlari, 2008). Additionally, carbonates may be the most effective sorbents for metals, as found by Halmos et al., (2015) in alkaline sediments. For Zn, largest effect of competition was found not only at alkaline conditions but in the sample with lowest clay content and highest acidity. This can be due to the increasing sorption of metals with higher affinity ( $\mathrm{Pb}, \mathrm{Cu}$ and $\mathrm{Cd}$ ) in the first case, as well as to the very low number of available sites at clay surfaces and increasing role of competition with $\mathrm{H}^{+}$ions (besides the metals with higher sorption) in the second one, as shown by the earlier mentioned study of Vidal et al., (2009). Highest effect of the competition on Cd sorption was found in the soil with the highest clay content. Although it is an alkaline soil where higher sorption could be expected, the high competition can be also related to the increasing sorption of metals with higher affinity than that of Cd. These metals displace $\mathrm{Cd}$ from the sorption sites of highest affinity, e.g. those on soil organic material, and it will be not sorbed on clay minerals due to its lower affinity (Helios-Rybicka \& Wojcik, 2012). Finally, no difference in the effect of competition on the sorption of $\mathrm{Pb}$ was found in the studied samples showing also the highest affinity of this metal to the studied soils even at competitive situation. This can be related to the fact that, among the studied metals, $\mathrm{Pb}$ can be characterized the most favorable electrochemical properties (like electronegativity, hydrolysis constants, softness) to form strong chemical bonding with most of the potential surfaces available in soil (Flogenac et al., 2007).

Higher sorption was expected in alkaline than in acidic soils as the amount of negative charge increases and the competition with $\mathrm{H}^{+}$decreases with alkalinity which is favourable for the sorption of cationic elements (Bradl, 2004). The difference between the sorption in acidic and alkaline soils is higher for metals with lower sorption (e.g. Cd and $\mathrm{Zn}$ ) as unfavourable conditions at acidic conditions reduce their sorption in soils, whereas metals with higher sorption may be still able to be adsorbed at higher degree. This observation is supported by the study of Serrano et al. (2009) who found that Pb retention on the surface hydroxyl groups occurred at a lower $\mathrm{pH}$ than that of $\mathrm{Cd}$, suggesting that the interaction for $\mathrm{Pb}$ takes place at $\mathrm{pH}$ where $\mathrm{Cd}$ only interacts with exchange sites. In acidic soils, L1-type sorption curve is characteristic suggesting no saturation due to less favourable conditions. Exceptions are $\mathrm{Cu}$ and $\mathrm{Pb}$ in samples with high TOC and with high clay content suggesting the high affinity of these metals to these soil components. According to Vytoplilová et al., (2015), high organic matter content may compensate the inhibitory effect of low $\mathrm{pH}$ on the sorption of $\mathrm{Cu}$ and $\mathrm{Pb}$ in soils. Additionally, Pokrovsky et al., (2012) found that 
bridging of $\mathrm{Pb}$ between montmorillonite and humic acid may be a potential sorption mechanism of this metal resulting in highly stable ternary complex in soils. So the high amount of smectite and organic matter in soil may result in high adsorption and saturation for both of these metals. On the contrary, $\mathrm{Cd}$ and $\mathrm{Zn}$ showed lower affinity (C-type curve) in the sample with highest acidity and low clay content suggesting strong competition with $\mathrm{H}^{+}$ions and low number of preferred sorption sites (Vidal et al. 2009). At competitive situation, $\mathrm{Zn}$ exhibits generally a maximum in its sorption curves except in the samples with high clay content showing lower rate of competition with increasing clay content. The clay minerals appear to be important soil components controlling the mobility of $\mathrm{Zn}$ in soils (Proust, 2015). For example, results of Nachtegaal \& Sparks (2004) showed that the complexation of Zn with the clay surface (kaolinite in this case) is thermodynamically favored over its adsorption onto goethite despite that $\mathrm{Zn}$ initially bonded to $\mathrm{FeOH}$ groups and the complex formation with kaolinite proceeded with aging only. In alkaline soils, however, very high affinities were found for all the studied metals (H-type curves). The almost complete retention of $\mathrm{Pb}$ and $\mathrm{Cu}$ at single element condition can be due to their precipitation as (hydroxy)carbonates on the one hand, and complexation with organic matter on the other, as discussed above. In case of competition, $\mathrm{Cu}$ exhibits complete retention in the sample with high clay and TOC content and $\mathrm{Pb}$ in samples with the highest $\mathrm{pH}$, further showing the preliminary role of organic matter in Cu sorption at alkaline conditions (Jalali \& Khanlari, 2008) and the increasing potential of $\mathrm{Pb}$ precipitation with increasing $\mathrm{pH}$ (Cao et al., 2003). In the other samples, their curves show saturation, but the role of precipitation in their immobilization still cannot be excluded. As mentioned earlier, the effect of competition is more expressed for metals with lower sorption, which is also shown by the sorption curves with a maximum for $\mathrm{Cd}$ in the sample with the lowest clay content and for $\mathrm{Zn}$ in all alkaline samples. No maximum in the sorption curve was found for $\mathrm{Cd}$ and $\mathrm{Zn}$ in the sample with high TOC and high clay content, which also shows their high affinities to these soil components.

The statistical analysis of the data to show the relationship between sorption capacities and soil properties has been of low efficiency in our case due to the low number of data and the high complexity of soils with respect to components and potential conditions affecting the sorption process. Zhang et al., (2012) also observed that there are additional factors overshadowing the influence the key ones controlling metal sorption in soils primarily. This can be due to the fact that soils generally contain large variety components supporting available surfaces for metal immobilization processes through surface complexation and precipitation. Despite this disadvantage, different sorption behavior of the metals with high and low sorption, respectively, was also demonstrated by these analyses and some observations could be also confirmed by them. Besides the effect of soil $\mathrm{pH}$, also soil CEC and clay content showed linear relationship with sorption capacities of $\mathrm{Cd}$ and $\mathrm{Zn}$, as found also by others (Bradl, 2004). A slight contradiction arises if samples are evaluated separately as no relation between Cd sorption and the soil clay content could be observed, only for Zn. Although clay content could be closely related to the CEC of the soil, this latter one is not recovered from the clay content solely but also from oxyhydroxide minerals and soil organic matter, of which association may enhance their sorption properties (Sipos et al., 2009). Further soil variables (TOC, BET, $\mathrm{Fe}_{\mathrm{d}}$ ) could not be related to the Qmax or RSC values of the studied metals. However, this does not mean the lack of the relationship necessarily. Interestingly, metals with lower sorption showed closer relationship with the studied soil properties than those with higher sorption, primarily at competitive situation. This can be explained by the phenomenon that $\mathrm{Cu}$ and $\mathrm{Pb}$ may occupy sites with different affinities, whereas $\mathrm{Cd}$ and Zn may be replaced from most of the sites and they are adsorbed only on those with the highest affinities (Vidal et al., 2009).

\section{CONCLUSIONS}

The higher sorption of $\mathrm{Pb}$ and $\mathrm{Cu}$ than that of $\mathrm{Cd}$ and $\mathrm{Zn}$ implies that the latter two metals may pose a higher risk to the environment in case of their release to the soil solution also in smectitic soils. Their sorption behavior is also affected by the competition stronger, resulting in an elevated risk even more. A kind of competition may arise also for $\mathrm{Pb}$ and $\mathrm{Cu}$ in calcareous soils where metalprecipitation occur as long as free carbonate is available, although $\mathrm{Cu}$ rather immobilized by soil organic matter at such conditions. Accumulation of clay minerals may significantly decrease the risk posed by $\mathrm{Cd}$ and $\mathrm{Zn}$ to the environment, primarily when smectites are associated with ironoxyhydroxides. At acidic soil conditions, however, only sorption of $\mathrm{Pb}$ and $\mathrm{Cu}$ may be significant in case of high amount of organic matter and smectites.

Occurrence of competition and precipitation during metal retention in soil also affect the shape of 
sorption curves. Metal sorption capacities (like Langmuir Qmax values) calculated on the basis of such curves may result in the over- or underestimation of the real sorption capacity of the soil. That is why a parameter directly showing the metal sorption in soil (like relative sorption capacity) should be also involved in the data evaluation.

The statistical analysis of the data to show the relationship between sorption capacities and soil properties was found to be of low efficiency in our case primarily due to the high complexity of soils with respect to components and potential conditions affecting the sorption process. Overshadowing effect of secondary factors may happen on the influence of key ones controlling metal sorption in soils. Consequently, elimination of one variable (variability of soil clay mineralogy in our case) is not enough to get a much deeper insight into soilmetal interaction, although several advantageous properties of smectites may be confirmed regarding metal sorption in soils.

\section{Acknowledgements}

This study was financially supported by the Hungarian Scientific Research Fund (OTKA K105009).

\section{REFERENCES}

Alloway, B.J., 2013. Sources of heavy metals and metalloids in soils. In: Alloway B.J. (ed): Heavy metals in soils: Trace metals and metalloids in soils and their bioavailability. Dordrecht, Springer Science\& Business Media, pp. 11-50.

Baghenejad, M., Javaheri, F. \& Moosavi, A.A., 2016. Adsorption isotherms of some heavy metals under conditions of their competitive adsorption onto highly calcareous soils of southern Iran. Archives in Agronomy and Soil Sciences, 62, 1462-1473.

Bradl, H., 2004. Adsorption of heavy metal ions on soils and soil components. Journal of Colloid and Interface Science, 277, 1-18.

Cao, X., Ma, L.Q., Chen, M., Hardison, D.W. \& Harris, W.G., 2003. Weathering of lead bullets and their environmental effects at outdoor shooting ranges. Journal of Environmental Quality, 32, 526-534.

Covelo, E.M., Vega, F.A. \& Andrade, M.L., 2007. Heavy metal sorption and desorption capacity of soils containing endogenous contaminants. Journal of Hazardous Materials, 143, 419-430.

Flogenac, K., Guilon, E. \& Aplincourt, M., 2007. Competitive sorption of metal ions onto a northeastern France soil. Isotherms and XAFS studies. Geoderma, 139, 180-189.

Fontes, M.P.F. \& Gomes, P.C., 2003. Simultaneous competitive adsorption of heavy metals by the mineral matrix of tropical soils. Applied
Geochemistry, 18, 795-804.

Giles, C.H., Smith, D. \& Hiutsaon, A., 1974. A general treatment and classification of the solute adsorption isotherm. I: Theoretical. Journal of Colloid and Interface Science 47, 755-765.

Halmos, L., Bozsó, G. \& Pál-Molnár, E., 2015. Adsorption properties of $\mathrm{Ni}, \mathrm{Cu}$, and $\mathrm{Zn}$ in young alkaline lake sediments in South Hungary (Lake Fehér, Szeged). Soil and Water Research, 10, 244251.

Helios-Rybicka, E. \& Wojcik, R., 2012. Competitive sorption/desorption of $\mathrm{Zn}, \mathrm{Cd}, \mathrm{Pb}, \mathrm{Ni}, \mathrm{Cu}$ and $\mathrm{Cr}$ by clay-bearing mining wastes. Applied Clay Science, 65-66, 6-13.

Jalali, M. \& Khanlari, Z.V., 2008. Effect of aging process on the fractionation of heavy metals in some calcareous soils of Iran. Geoderma, 143, 2640.

Madzhieva, S., Minkina, T., Pinskiy, D., Bauer, T. \& Sushkova, S., 2014. The role of soil's particle-size fractions in the adsorption of heavy metals. Eurasian Journal of Soil Science, 3, 197-205.

McLaughlin, M.J., Zarcinas, B.A., Stevens, D.P. \& Cook, N., 2000. Soil testing for heavy metals. Communications in Soil Science and Plant Analysis, 31, 1661-1700.

Mehra, O.P. \& Jackson, M.L., 1960. Iron oxide removal from soils and clays by a dithionite-citrate system buffered with sodium bicarbonate. Clays and Clay Minerals, 7, 317-327.

Morera, M.T., Echeverría, J.C., Mazkarián, C. \& Garrido, J.J., 2001. Isotherms and sequential extraction procedures for evaluating sorption and distribution of heavy metals in soils. Environmental Pollution, 113, 135-144.

Nachtegaal, M. \& Sparks, D.L., 2004. Effect of iron oxide coatings on zinc sorption mechanisms at the clay-mineral/water interface. Journal of Colloid and Interface Science, 276, 13-23.

Pokrovsky, O.S., Probst, A., Leviel, E. \& Liao, B., 2012. Interactions between cadmium and lead with acidic soils: experimental evidence of similar adsorption patterns for a wide range of metal concentrations and the implications of metal migration. Journal of Hazardous Materials, 199200, 358-366.

Pozinovsky, A.A., Allen, H.E. \& Ackerman, A.J., 2007. Copper activity in soil solutions of calcareous soils. Environmental Pollution, 145, 1-6.

Proust, D., 2015. Sorption and distribution of $\mathrm{Zn}$ in a sludge-amended soil: influence of the soil clay mineralogy. Journal of Soils and Sediments, 15, 607-622.

Rutkowska, B., Szulc, W. \& Bomze, K., 2013. Effects of soil properties on copper speciation in soil solution. Journal of Elementology, 18, 695-703.

Sangiumsak, N. \& Punrattanasin, P., 2014. Adsorption behavior of heavy metals on various soils. Polish Journal of Environmental Studies, 23, 853-865.

Serrano, S., Garrido, F., Campbell, C.G. \& García- 
Gonzalez, M.T., 2005. Competitive sorption of cadmium and lead in acid soils of Central Spain. Geoderma, 124, 91-104.

Serrano, S., O’Day, P.A., Vlassopoulos, D., GarcíaGonzalez, M.T. \& Garrido, F., 2009. A surface complexation and ion exchange model of $\mathrm{Pb}$ and Cd competitive sorption on natural soils. Geochimica et Cosmochimica Acta, 73, 543-558.

Sipos, P., 2010. Sorption of copper and lead on soils and soil clay fractions with different clay mineralogy. Carpathian Journal of Earth and Environmental Sciences 5(2), 111-118.

Sipos, P., Németh, T., Kovács Kis, V. \& Mohai, I., 2009. Association of individual soil mineral constituents and heavy metals as studied by sorption experiments and analytical electron microscopy analyses. Journal of Hazardous Materials, 168, 1512-1520.

Sparks, D. 2002. Environmental soil chemistry. San Diego, Academic Press.

Szalai, Z. 2008. Spatial and temporal pattern of soil $p H$ and Eh and their impact on solute iron content in a wetland (Transdanubia, Hungary). AGD Landscape and Environment, 2, 34-45.

Turpault, M.P., Righi, D. \& Utérano, C., 2008. Clay minerals: Precise markers of the spatial and temporal variability of the biogeochemical soil environment. Geoderma, 147, 108-1115.

Uddin, M.K., 2017. A review on the adsorption of heavy metals by clay minerals, with special focus on the past decade. Chemical Engineering Journal, 308, 438-462.

Received at: 18. 03. 2017

Revised at: 23. 07. 2017

Accepted for publication at: 27. 07. 2017

Published online at: 02. 08. 2017
Xiong, X., Stagnitti, F., Túróczy, N., Allinson, G., Li, P., Nieber, J., Steenhuis, T.S., Parlange, J.-Y., Leblanc, M., Ziogas, A.K., Ferreire, A.J.D. \& Keizer, J.J., 2005. Competitive sorption of metals in water-repellent soils: Implications for irrigation recycled water. Australian Journal of Soil Research, 43, 351-356.

Vidal, M., Santos, M.J., Abrao, T., Rodriguez, J. \& Rigol, A., 2009. Modelling competitive metal sorption in a mineral soil. Geoderma, 149, 189198.

Violante, A., Krishnamutri, G.S.R. \& Pigna, M., 2008. Factors affecting the sorption-desorption of trace elements in soil environments. In: Violante A., Huang P.M., Gadd G.M. (eds): Biophysicochemical processes of heavy metals and metalloids in soil environments. New York, John Wiley and Sons, pp. 169-214.

Vytopílová, M., Tejnecký, V., Borůvka, L. \& Drábek, O., 2015. Sorption of heavy metals in organic horizons of acid forest soils at low added concentrations. Soil and Water Research, 10, 1-9.

Wong, J.W.C., Li, K.L., Zhou, L.X. \& Selvam, A., 2007. The sorption of $\mathrm{Cd}$ and $\mathrm{Zn}$ by different soils in the presence of dissolved organic matter from sludge. Geoderma, 137, 310-317.

Zhang, F., Xiaoxia, O.U., Chen, S., Ran, C. \& Quan, X., 2012. Competitive sorption and desorption of copper and lead in some soil of North China. Frontiers in Environmental Science and Engineering 6, 484-492. 